\title{
O uso de palmadas e surras como prática educativa
}

\author{
Lidia Natalia Dobrianskyj Weber \\ Ana Paula Viezzer \\ Olivia Justen Brandenburg \\ Universidade Federal do Paraná
}

\begin{abstract}
Resumo
Esta pesquisa identificou as práticas educativas parentais, com ênfase em castigos e punições corporais, por meio do relato de estudantes. Responderam a um questionário com 61 questões, 472 crianças e adolescentes de ambos os sexos e com idade entre oito e 16 anos. A maioria dos participantes relatou que já recebera punições corporais $(88,1 \%)$ e castigos $(64,8 \%)$. Sobre punições corporais, $86,1 \%$ apanharam da mãe e $58,6 \%$ apanharam do pai; $36,9 \%$ dos participantes relataram que já ficaram machucados. A maioria dos participantes apanhou nas nádegas $(64,7 \%)$, e os punidores utilizaram mais freqüentemente as próprias mãos $(62,3 \%)$, embora cinto $(43,0 \%)$ e chinelo $(42,3 \%)$ também tenham servido para punir. A avaliação que os participantes fizeram sobre os métodos disciplinares revelou uma contradição: $75,2 \%$ concordaram que, quando fazem coisas erradas, as crianças devem apanhar, mas somente 34,5\% afirmaram que utilizarão punições corporais em seus filhos, e um número considerável $(27,1 \%)$ afirmou estar em dúvida. As implicações do uso da punição corporal foram discutidas.
\end{abstract}

Palavras-chave: punição corporal; práticas educativas; violência contra a criança

\begin{abstract}
The use of spanking and physical punishment in parenting. The aim of this study was to identify parenting practices that included punitive interactions: physical punishment and nonphysical punishment. A 61-item survey was developed and given to 472 students (aged 8-16 years). Results of the survey showed that: the majority of the participants claimed that had received physical punishment $(88,1 \%)$ and nonphysical punishment $(64,8 \%) ; 86,1 \%$ was spanked by mothers, and $58,9 \%$ by fathers; $36,9 \%$ reported that they had been hurt when spanked; most of the students $(64,7 \%)$ were hit on their buttocks; $62,3 \%$ was spanked with hands, but some objects as belt $(43,0 \%)$ and slippers $(42,3 \%)$ were also used. The evaluation made by the participants about physical punishment revealed a contradiction: while 75,2\% agreed children must be spanked when they misbehave, only $34,5 \%$ said that they intend to spank their children in the future. Implications for the use of physical punishment were discussed.
\end{abstract}

Keywords: physical punishment; parenting; violence against children

\section{Qui bene amat bene castigat}

$\mathrm{N}$ ão poupes ao menino a correção: se tu o castigares com a vara, ele não morrerá; castigando-o com a vara salvarás sua vida da morada dos mortos" (Bíblia Sagrada, Provérbios 23: 13-14). Este, entre outros provérbios bíblicos, mostra que as indicações para o uso de punição corporal como método disciplinar remontam há milênios. Os ditados populares, nas diferentes culturas, também indicam esta maneira de educar uma criança e oferecem regras a serem seguidas: "ama as crianças com o coração, mas educa-as com tua mão" (provérbio russo); "quem não foi bem castigado com a vara, não foi bem educado" (provérbio grego). A vinculação da punição corporal com a disciplina vem sendo transmitida ao longo de muitas gerações como verdades inquestionáveis, consideradas modelos a serem seguidos pelos pais na educação de seus filhos.

Nos Estados Unidos da América, pesquisas demonstram que mais de $90 \%$ dos pais batem em seus filhos (Grasiano \& Namaste, 1990; Murphy-Cowan \& Stringer, 1999; Straus \& Stewart, 1999), e um percentual igualmente alto tem sido encontrado em diferentes países e culturas (Azevedo \& Guerra, 2002). Por vários séculos, a imagem da infância foi aquela expressa por Santo Agostinho (354-430 d.C.), que afirmava não existir inocência infantil. Para ele, a criança trazia o pecado original desde o ventre de sua mãe, e assim, representava a condenação da humanidade, e tendia sempre para o mal. Se a infância era a personificação do pecado, a redenção deste 
pecado deveria ocorrer pelo combate da infância, pela anulação da sua corrupção, justificando as ameaças, varas e palmatórias (Ariès, 1978; Badinter, 1985; Guerra, 1998). O castigo físico e o infanticídio foram permitidos por lei durante muitos séculos; a primeira lei conhecida proibindo o infanticídio só foi promulgada no ano 374 d.C. (Badinter,1985; Gallardo, 1988; Marinopoulos, 1998; Roig \& Ochotorena, 1993; Postman, 1999).

Rousseau, no século XVIII, marcou um novo conceito de infância: ela não era corrupta, mas poderia ser corruptível. Não era algo contra o que se devesse lutar, mas era preciso cuidá-la para que não se deformasse em erro (Mello Neto, 1998). A criança começou a ser valorizada como um ser humano que necessita de cuidados e atenção especiais. Esse período marcou uma maior aproximação entre os filhos e seus pais verdadeiros, pois, nos séculos anteriores, a criança ficava sob cuidados de pessoas alheias à família, mas gradativamente ela passou a ter um contato mais intenso e também afetivo com seus pais (Ariès, 1978; Roig \& Ochotorena, 1993).

A valorização da criança foi muito tardia. Legalmente, ela só se tornou um sujeito de direitos no século XX, em 1959, na Assembléia Geral da ONU, na qual foi promulgada a Declaração dos Direitos da Criança. A conscientização sobre a particularidade infantil levou muitos estudiosos a pesquisarem e conhecerem melhor todo o processo de desenvolvimento infantil, as práticas educativas usadas pelos pais e suas relações com o comportamento dos filhos. Neste contexto surge o debate sobre o uso da punição corporal, prática milenar que se perpetua até os dias atuais.

Skinner (1953/1976), já na década de 1950, mostravase contrário ao uso da punição corporal para ensinar comportamentos adequados. Apesar de a punição corporal produzir efeito imediato que mantém a utilização desta prática educativa, há efeitos nocivos, tais como emoções de raiva e medo e comportamentos de esquiva diante da pessoa que pune.

As respostas emocionais geradas pela punição (choro, medo, ansiedade, raiva) podem também ser condicionadas, por meio do condicionamento pavloviano, a aparecerem em outras ocasiões não punitivas. Assim, a punição do comportamento de mentir de uma criança pode levá-la a apresentar os mesmos comportamentos emocionais advindos com a punição (choro, rubor, suor) em uma situação em que precise se expressar verbalmente.

Além da eliciação de comportamentos emocionais, há o condicionamento de comportamentos de fuga e esquiva (por meio do reforçamento negativo), que reduzem ou livram a criança da estimulação aversiva ou pré-aversiva, ou seja, a criança pode simplesmente passar a fugir e/ou evitar o agente punidor. Portanto, os comportamentos inadequados continuam no repertório comportamental da criança, mas deixam de ser punidos quando ela esconde-se ou mente para seus pais. Além de tudo, Skinner enfatiza que punir um comportamento não faz com que o comportamento adequado apareça e, ao lado disso, reforça o comportamento dos pais que pas- sarão a ter maior probabilidade de utilizar a punição corporal em outras ocasiões semelhantes.

Existe ainda outro aspecto importante em relação às punições, estudado pela Análise do Comportamento, o fenômeno chamado desamparo aprendido (Seligman, 1975/1977). O desamparo aprendido é a incapacidade de aprendizagem de novas respostas de esquiva diante de uma história de exposição a estímulos aversivos não contingentes a qualquer resposta. Se as punições, especialmente corporais, não são contingentes e dependem do humor dos pais, pode acontecer que ocorra o fenômeno de desamparo, e a criança simplesmente não saiba o que fazer, não saiba qual resposta deverá emitir para evitar as punições. O trágico, como ressalta Matos (1982), é que a pessoa pode generalizar esse comportamento para outras situações aversivas.

Ainda, na aplicação da punição corporal pode ocorrer uma associação entre a dor que a criança sente e o amor em relação aos seus pais. Geralmente a punição corporal é acompanhada por um discurso dos pais que amam a criança e que batem para o bem dela (Cornet, 1997). Assim, a associação entre a dor e o amor, por meio de emparelhamento de estímulos, vai ensinar a criança a usar o mesmo método em outras situações de sua vida ou, ainda, a suportar situações aversivas e disfuncionais que deveriam ser terminadas (Weber, 2001).

Se o comportamento de punir é reforçador tanto para os pais quanto para os filhos, forma-se um círculo vicioso. Este círculo perpetua-se pela falta de conhecimento dos efeitos deste método e de outros que possam substituir a punição corporal, como também dos próprios efeitos que reforçam o comportamento de quem pune e, portanto, ajudam a manter tal comportamento. Justamente pelo desconhecimento, para muitos pais bater é considerado a melhor forma de disciplinar os filhos. Porém, disciplinar possui diferentes significados. A maioria das definições de disciplinar encontra-se em dois grandes campos: controlar, punir e corrigir; ou ensinar, guiar e influenciar. Os estudos atuais (Garbarino, 1999; Hyman, 1997; Patterson, Reid, \& Dishion, 1992; Straus, 2000, 2001), em sua maioria, mostram que a segunda definição é mais efetiva na produção de comportamentos desejados.

O debate "bater versus não bater" apresenta alguns complicadores. Em primeiro lugar, definições operacionais não diferenciam perfeitamente os termos palmada, surra, punição corporal, espancamento. Enquanto a punição corporal é definida como "punição aplicada em qualquer parte do corpo e de qualquer tipo", a famosa palmada (spanking) define-se como "um tapa, aplicado com a mão aberta, nas nádegas ou em extremidades do corpo, visando a modificação do comportamento" (Baumrind, 2001, p. 1). Em segundo lugar, este debate volta-se para a ética e os direitos da criança. Em terceiro lugar, a questão dos efeitos da palmada, da punição corporal, da surra leve, do psicotapa, é controversa entre leigos e especialistas.

Os dados de algumas pesquisas empíricas apontam para a condenação do uso da punição corporal (Bryant \& Range, 1995; Glueck \& Glueck, 1968; Gomide, 2001; Patterson et al., 
1992; Reid, Taplin, \& Lorber, 1981; Welsh, 1976; Wilson \& Hernstein, 1985;). Entretanto, Larzelere (2000) defende o uso de punição corporal não muito severa para crianças de 2 a 6 anos. Um estudo liderado pelo mesmo autor indicou que a punição moderada aliada ao diálogo (reasoning) foi a forma mais eficaz de corrigir os erros de crianças pequenas. Os autores concluíram que a maneira pela qual a punição é usada é mais importante do que o tipo dela (física ou não), porque as duas formas demonstraram eficácia quando combinadas com diálogo (Larzelere, Schneider, Larson, \& Pike, 1996).

Para Straus (1991), autor que tem forte posição contra a palmada, Larzelere somente tem certa razão em afirmar que a punição corporal traz efeitos positivos pelo fato de ela ser imediata, ou seja, a criança pára de emitir o comportamento inadequado. Este "efeito positivo" traz benefício para os pais, ou seja, a obediência imediata da criança. Porém é amplamente discutido pela Análise do Comportamento: é muito mais provável que se obtenham conseqüências imediatas apresentando um estímulo punitivo do que apresentando um reforçador (Skinner, 1953/1976; Sidman, 1995), e isso "significa que uma pessoa, provavelmente, acha mais fácil aprender técnicas de controle aversivo do que técnicas de reforço. No entanto, isso não significa que as técnicas aversivas sejam melhores" (Catania, 1999, p. 128). Esse efeito positivo imediato pode ser alcançado igualmente por uma punição nãofísica, como mostram pesquisas que compararam métodos disciplinares que fazem uso da punição corporal (a palmada) com aqueles que não o fazem (o time out), e chegaram à conclusão de que os dois métodos funcionam igualmente (Day \& Roberts, 1983; Roberts \& Powers 1990).

Straus (1991) ainda defende que a punição corporal pode ser eficaz no instante em que é aplicada, mas ela traz muitos prejuízos a longo prazo, não somente para o indivíduo como também para os outros com quem convive, devido ao risco de delinqüência, de criminalidade violenta, de violência contra o cônjuge (Straus, 1991; Straus \& McCord, 1998).

Pesquisas realizadas com o objetivo de relacionar o recebimento de punição corporal com alguma variável comportamental da criança encontraram prejuízos para o desenvolvimento infantil: as crianças que apanhavam (comparadas com as que não apanhavam) apresentaram auto-estima mais baixa (Larzelere, Klein, Schumm, \& Alibrando, 1990), comportamento mais agressivo (Stormshak, Bierman, McMahon, \& Lengua, 2000; Strassberg, Dodge, Pettit, \& Bates, 1994), altos níveis de sintomas psiquiátricos e baixo bem-estar geral (Bachar, Canetti, Bonne, DeNour, \& Shaley, 1997).

A ineficácia da punição corporal refere-se ao princípio de qualquer punição: não mostra o que deve ser feito, apenas o que não deve. A punição enfoca o erro e não ensina o certo (Bettner \& Lew, 2000; Sidman, 1995; Skinner, 1953/1976); então, tal comportamento pode deixar de ser emitido por algum tempo, mas não necessariamente há a aprendizagem de qual deve ser o comportamento adequado: "quando muito, punição somente o ensina o que não fazer" (Sidman, 1995, p. 60). Para Sidman, além de a punição não ser eficaz na eliminação de um comportamento em longo prazo, não contribui na construção de um repertório comportamental mais adequado e está inserida num contexto coercitivo. Sidman (1995) afirma que "coerção entra em cena quando nossas ações são controladas por reforçamento negativo ou punição" (p. 51).

Para mudar as atitudes dos pais é preciso entender o que os leva a baterem em seus filhos. Em verdade, a punição corporal é utilizada principalmente pela produção de um efeito imediato, mas também pela falta de conhecimento dos pais sobre as fases do desenvolvimento infantil, sobre outras estratégias educativas e sobre os malefícios da educação coercitiva. A falta de conhecimento dos pais pode produzir sentimentos de incompetência e irritação por não saber como se comportar diante do filho. A pesquisa de Graziano e Namaste (1990) mostra que $90,7 \%$ dos sujeitos relataram que seus pais mostraram expressões de irritação quando bateram, e Cornet (1997) afirma que os pais descontam nos filhos suas irritações presentes ou mesmo passadas (pais que apanharam na infância) e tornam a agressividade um círculo vicioso. Tendo em vista que as emoções alteram a probabilidade de ocorrência de comportamentos públicos (Skinner, 1953/1976), compreende-se que quando os pais estão irritados e nervosos, há maior probabilidade de eles baterem em um nível de violência maior apenas por um pequeno comportamento inadequado da criança. Neste caso, a punição corporal deixa de ter um caráter educativo para transformar-se realmente em falta de autocontrole dos pais e levar à agressão.

Frias-Armenta (1999) afirma que os pais não têm conhecimento do limite entre punição corporal disciplinar e abuso infantil; disso pode-se concluir que a passagem da punição para o abuso é muito frágil. A punição corporal aparece, então, como um fator de risco para o abuso e, por isso, deve ser evitada (Straus, 2001; Weber, Viezzer, \& Brandenburg, 2003; Whipple \& Richey, 1997). Em verdade, não existe uma clara definição da diferença entre o que é punição disciplinar e abuso. A diferença estaria na intenção ou nas marcas físicas?

As pesquisas relatadas mostraram problemas com o uso de punições corporais como uma prática educativa e, portanto, que os pais atuais precisam ter acesso ao conhecimento de outras práticas educativas que sejam eficazes para criar e manter um repertório de comportamentos adequados, ajudar o desenvolvimento de habilidades sociais em seus filhos e manter uma dinâmica familiar com muita responsividade, afeto e comprometimento. Eventualmente será preciso utilizar alguma estratégia para reduzir ou eliminar comportamentos inadequados e/ou transgressões aos limites. Porém, se o uso da disciplina positiva (uso de reforçadores) for sistemática, se o estabelecimento de regras (limites) for consistente e lógico, se houver supervisão constante, modelos positivos, incentivo à autonomia da criança e fortalecimento de sua autoestima, não sobrará muito espaço para a ocorrência de comportamentos inadequados significativos. Os poucos que surgirem poderão ser resolvidos com estratégias menos dolorosas e indignas do que as punições corporais, tais como time out, uso de conseqüências lógicas, adiamento de reforçamento, entre outras. 
Esta pesquisa teve o objetivo de descrever a incidência de práticas educativas parentais coercitivas, especialmente o uso da punição corporal utilizada contingentemente ao comportamento de crianças e adolescentes de diferentes níveis socioeconômicos.

\section{Método}

\section{Participantes}

Tomaram parte no estudo quatrocentas e setenta e duas crianças ( $4^{\underline{a}}$ e $5^{\underline{a}}$ séries $)$ e adolescentes $\left(7^{\underline{a}}\right.$ e $8^{\underline{a}}$ séries $)$ de três escolas da cidade de Curitiba: uma escola particular; uma escola municipal e um colégio estadual da região metropolitana de Curitiba. Os alunos da escola particular apresentavam o nível socioeconômico mais elevado dentre os três grupos e os da escola estadual provinham de um nível socioeconômico mais baixo; os alunos da escola municipal estavam em uma posição intermediária entre as outras duas. A idade média dos alunos de $4^{\mathrm{a}}$ e $5^{\mathrm{a}}$ séries foi 10,4 anos, com desvio padrão de 1,42 ; a idade média dos alunos de $7^{\text {a }}$ e $8^{\underline{a}}$ séries foi 13,9 anos, com desvio padrão de 0,72 .

\section{Instrumentos}

Foi utilizado um questionário elaborado pelas pesquisadoras (contendo 60 questões fechadas e uma questão aberta) com o objetivo principal de identificar as práticas disciplinares utilizadas por seus pais ou familiares e o modo como são aplicadas. Além disso, outras perguntas visaram investigar a opinião das crianças e dos adolescentes sobre o uso de punições corporais e de castigos (não corporais) em sua própria experiência e a maneira como agiriam com seus filhos. A construção do instrumento foi teórico-empírica: 1) inicialmente foram utilizadas fontes bibliográficas (Azevedo \& Guerra, 1997; Bodenhamer, 1995; Guerra, 1998; Hyman, 1997; Sidman, 1995); 2) entrevistas não diretivas com pais, crianças e ado- lescentes; 3) pré-teste do instrumento com 10 crianças e 10 adolescentes; 4) aperfeiçoamento do questionário, que se definiu com a seguinte estrutura: dados gerais e dinâmica familiar, tipos de punição e castigo, forma de aplicação de punição e de castigo (instrumento utilizado, freqüência, intensidade, agente punidor e ocasião), opiniões e sentimentos dos participantes.

\section{Procedimento}

A escolha dos sujeitos seguiu o critério de idade (criança e adolescente) e das escolas seguiu critério do nível socioeconômico (baixo, médio e alto). As direções de três escolas de diferentes níveis socioeconômicos foram contatadas e foi obtida permissão escrita para realização da pesquisa e a devida aplicação nas dependências da escola. $\mathrm{O}$ questionário foi aplicado coletivamente para os alunos em suas salas de aula, com a recomendação de não haver nenhuma identificação do participante para não inibir possíveis respostas que pudessem trazer desconforto. Foram tomados todos os cuidados éticos necessários, como anonimato dos sujeitos e das escolas, e permissão dos responsáveis pelos participantes, para realização da pesquisa.

\section{Resultados e Discussão ${ }^{1}$}

A análise dos dados mostrou pouca diferença em relação à idade e ao nível socioeconômico dos participantes (definido pelas escolas que freqüentavam) e, por este motivo, os dados serão apresentados para o conjunto de participantes, e serão analisadas somente as diferenças que se mostraram estatisticamente significativas entre aquelas variáveis. O primeiro resultado a ser discutido refere-se à questão do "bater versus não bater" e "castigar versus não castigar". A Figura 1 mostra o relato das crianças sobre o uso de castigos não corporais (como, por exemplo, ficar sem assistir à TV, não receber mesada, não poder sair de casa) e punições corporais pelos pais.

$60,2 \%$

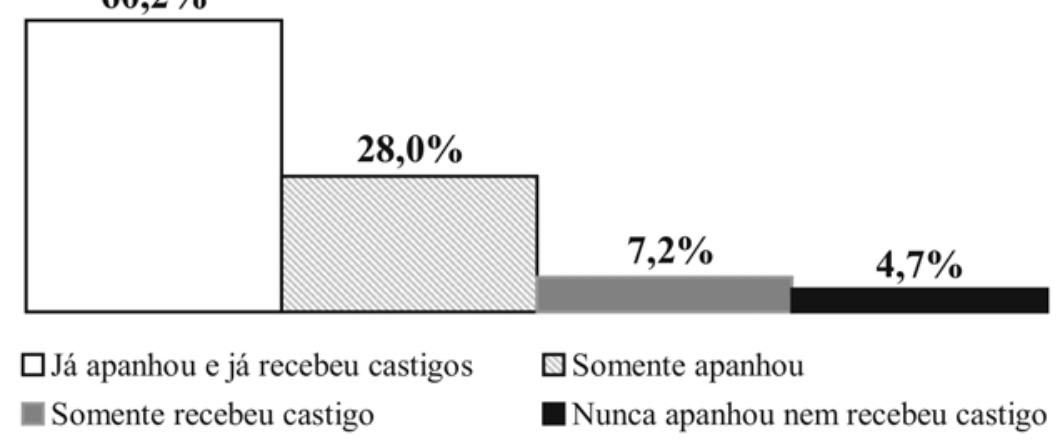

Figura 1. Porcentagem de estudantes das três escolas pesquisadas em relação ao recebimento de punições corporais e castigos. 
Pode-se observar, na Figura 1, que a maioria das crianças e adolescentes já recebeu punição corporal. Tal resultado é confirmado por outras pesquisas nos EUA, em que mais de $90 \%$ das crianças apanham (Grasiano \& Namaste, 1990; MurphyCowan \& Stringer, 1999; Straus \& Stewart, 1999), e pesquisas em diferentes países e culturas (Azevedo \& Guerra, 2002). A Figura 1 também mostra que um maior número de participantes recebeu punições corporais em relação ao recebimento de somente castigos, resultado este que se repete na Figura 2.

A

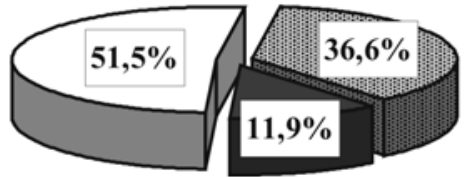

nunca apanhou $\square$ só uns tapas 圈 tapas e surras

B

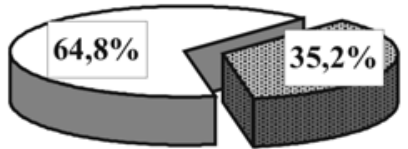

$\square$ já recebeu castigo 圈 nunca recebeu castigo

Figura 2. Porcentagem de estudantes das três escolas pesquisadas que receberam punições corporais (A) e castigos (B).

A Figura 2 mostra o relato verbal das crianças sobre a maior ou menor intensidade das punições corporais. Considerando somente a punição corporal, a maioria absoluta das crianças relatou que recebem somente tapas; em segundo lugar, ficaram aquelas que recebem tanto tapas quanto punições de maior intensidade (surras) e, por fim, as que não recebem punições. Os castigos foram menos utilizados que a punição corporal. Isso pode ser explicado pelo fato de a punição corporal ser um método mais fácil de ser aplicado, o efeito é imediato e isso reforça o comportamento dos pais de baterem (Skinner 1953/1976). Já os castigos exigem um planejamento e uma maior monitoria por parte dos educadores, os quais devem estar atentos para que a criança cumpra o castigo.

Apesar de a maioria das crianças ter relatado que já recebera punições corporais e castigos, os dados mostraram que dentre os relatos das crianças que nunca receberam nenhum dos dois, a grande maioria pertencia à escola de menor poder aquisitivo $(69,2 \%)$, sendo possível afirmar que existe diferença entre os grupos de níveis socioeconômicos em relação aos relatos de punições e castigos utilizados pelos pais $\left(\chi^{2}=5,903\right.$; $g l=1 ; p=0,015)$. Este dado difere do resultado de Azevedo e Guerra (2001), que encontraram maior percentual de crianças que nunca apanharam em classes mais favorecidas.
Na Figura 3, pode-se verificar, entre os participantes que relataram ter recebido punições corporais, qual foi o instrumento utilizado para bater, e em que lugar do corpo eles foram atingidos.

A

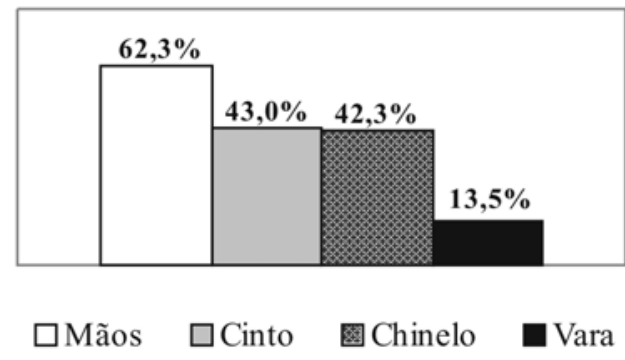

B

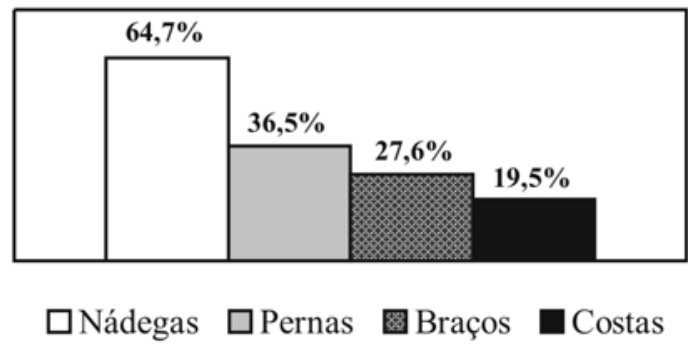

Figura 3. Porcentagem de respostas positivas em cada categoria de punição recebida (A) e o lugar do corpo que foi mais atingido (B).

As mãos foram o meio mais utilizado para bater. Este comportamento parental geralmente é emitido em situações em que os pais sentem raiva pelo comportamento da criança e não têm repertório para exercer um comportamento de autocontrole. Como indica o depoimento de uma participante: "eu acho que nem todos os pais sabem por que estão batendo em seus filhos" (Ana, 11 anos). Objetos como o cinto e o chinelo foram também muito utilizados, talvez justamente por serem objetos que estão próximos da pessoa que pune.

Quanto ao lugar do corpo em que os participantes relataram ter apanhado, as nádegas estavam em primeiro lugar, porém muitas outras áreas do corpo também foram citadas, como, por exemplo, pernas, braços e costas. Bater com a palma da mão nas nádegas é a definição de palmada (spanking), e as outras formas aqui apresentadas estão incluídas como punição corporal, de acordo com Baumrind (2001).

A Figura 4 apresenta os dados relacionados com o relato das crianças sobre as pessoas que bateram mais freqüentemente nas crianças e nos adolescentes. O percentual obtido de cada aplicador representa a freqüência de respostas positivas independentemente dos outros aplicadores. 


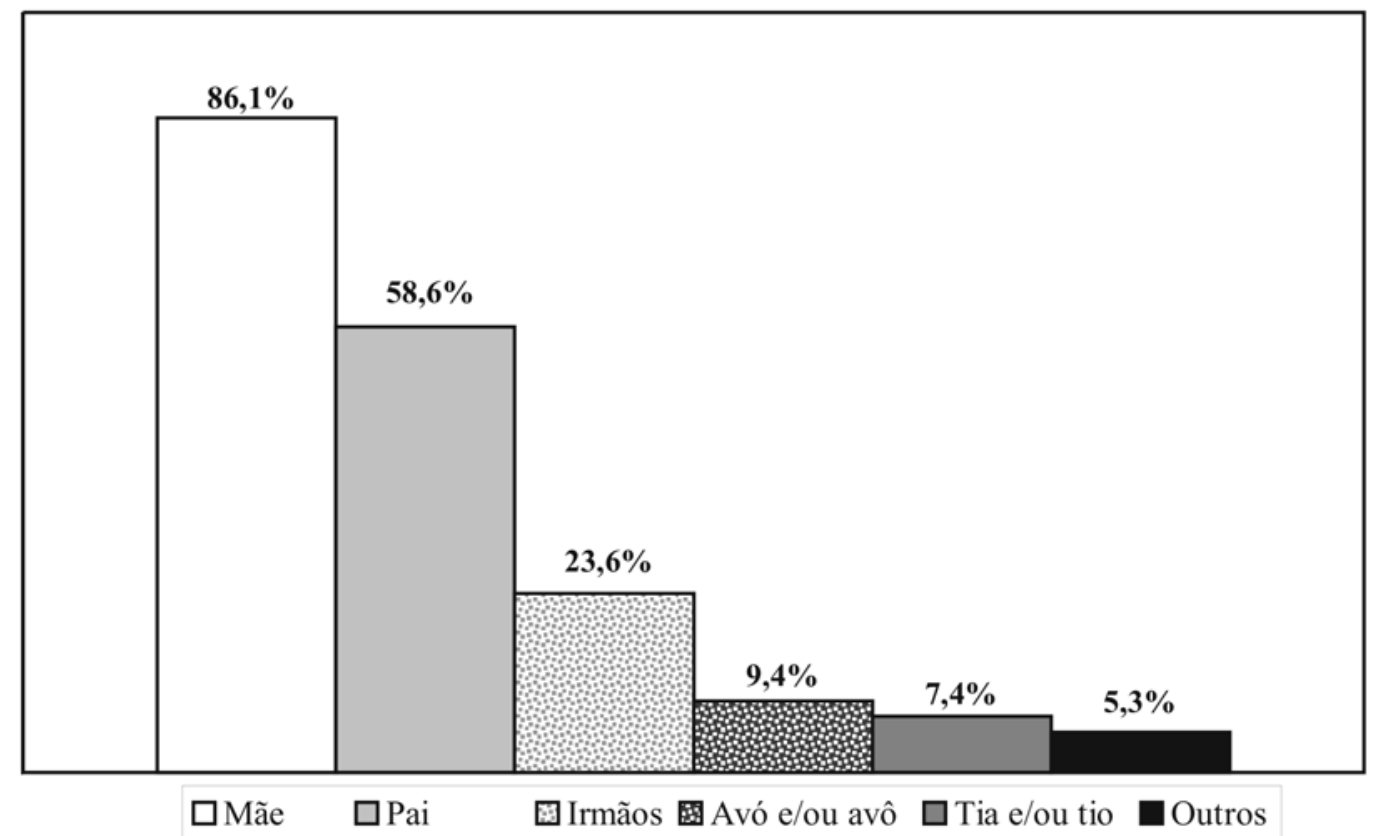

Figura 4. Porcentagem das pessoas que aplicaram punições corporais obtida pelo relato dos alunos.

A Figura 4 mostra que a mãe utilizou a punição corporal como método disciplinar com maior freqüência; o pai apareceu em segundo lugar, sendo a diferença entre os dois, estatisticamente significativa $\left(\chi^{2}=10,4 ; g l=1 ; p<0,05\right)$. Talvez isso ocorra pelo fato de normalmente serem as mães as pessoas que mais se ocupam com a disciplina das crianças. Dois fatores que também podem contribuir para essa alta porcentagem são: o grande número de mães que não trabalham $(30,2 \%)$ e assim têm maior oportunidade de estarem próximas aos filhos; a existência de famílias monoparentais maternas $(14,0 \%)$. Em trabalhos que investigam denúncias de maustratos, a mãe também aparece como principal agressora (Weber, Viezzer, Brandenburg, \& Zocche, 2002).

Não houve relação entre idade de pais e mães com o uso de palmadas e surras, ou seja, tanto os pais mais velhos quanto os mais novos aplicaram punições corporais da mesma forma $\left(\chi^{2}=2,072 ; g l=1 ; p=0,150\right.$ para o pai; $\chi^{2}=2,508 ; g l=1 ; p=$ 0,113 para a mãe). A escolaridade de pais e mães também não influenciou na aplicação da punição corporal: tanto pais e mães que têm nível superior quanto aqueles que têm escolaridade mínima utilizavam esta prática $\left(\chi^{2}=0,168 ; g l=1 ; p=\right.$ 0,682 para os pais; $\chi^{2}=3,318 ; g l=2 ; p=0,190$ para as mães). Morris (1996) também encontrou que o nível educacional não influenciou significativamente o fato de as mães usarem ou não a punição corporal.

Não houve diferença significativa entre o recebimento de tapas e surras e as diferentes idades das crianças e adolescentes $\left(\chi^{2}=0,976 ; g l=2 ; p=0,614\right)$. Por outro lado, houve diferença significativa entre os gêneros $\left(\chi^{2}=10,463 ; g l=1 ; p=0,001\right)$, pois de todos os participantes que afirmaram ter recebido "somente tapas", a maioria foi meninas $(58,8 \%)$, enquanto daqueles que afirmaram ter recebido "surras", a maioria foi meninos
$(57,2 \%)$. Portanto, pode-se afirmar que os meninos receberam punição corporal mais severa do que as meninas.

A freqüência de crianças que relataram terem ficado machucadas ou com marcas depois de apanhar foi de 36,9\%, das quais $32,8 \%$ disseram ter ficado "pouco machucadas" e $4,1 \%$ disseram ter ficado "muito machucadas", sendo a interpretação de "pouco" e "muito" de cada criança. Mesmo com a interpretação subjetiva dos participantes, o dado revela que há um número considerável de crianças que afirmaram serem maltratadas em seus lares, o que demonstra que a violência contra a criança ainda está sendo aceita socialmente. Isto confirma os estudos de Straus (2000) e de Whipple e Richey (1997) de que a palmada é um fator de risco para o abuso infantil, ressaltando que, em uma pesquisa sobre denúncias de maus-tratos, o principal motivo dado pelo agressor para a violência foi que ele "queria educar o seu filho" (Weber, Viezzer, Brandenburg, \& Zocche, 2002).

O fator de risco da palmada pode estar ligado com o tipo de instrumento utilizado para punir a criança. Afirmaram ficar machucadas, $32,3 \%$ das crianças que apanharam com a mão $\left(\chi^{2}=6,202 ; g l=1 ; p=0,013\right) ; 49,7 \%$ que apanharam de chinelo $\left(\chi^{2}=21,479 ; g l=1 ; p<0,001\right) ; 56,3 \%$ que apanharam de cinto $\left(\chi^{2}=49,447 ; g l=1 ; p<0,001\right) ; 67,9 \%$ que apanharam de vara $\left(\chi^{2}=26,689 ; g l=1 ; p<0,001\right) ; 72,7 \%$ que apanharam de mangueira $\left(\chi^{2}=6,233 ; g l=1 ; p=0,013\right) ; 100 \%$ que apanharam de cabo de vassoura $\left(\chi^{2}=34,071 ; g l=1 ; p<0,001\right) ; 100 \%$ que apanharam de corrente $\left(\chi^{2}=17,531 ; g l=1 ; p<0,001\right)$. Pode-se perceber que o percentual de crianças que ficaram machucadas é crescente de acordo com o tipo do instrumento utilizado. A observação sobre utilização de diferentes tipos de instrumentos é relevante por representar um fator de risco de violência contra a criança. 
Não foi encontrada nenhuma relação entre gênero e ficar ou não machucado $\left(\chi^{2}=1,479 ; g l=1 ; p=0,224\right)$, ou seja, meninas e meninos afirmaram ficar machucados igualmente. Porém, se os meninos levaram mais surras, supõe-se que deveriam ficar mais machucados, o que não foi constatado. A partir disso, levanta-se a hipótese de que a avaliação do que seja ou não um machucado é muito subjetiva. Esta mesma hipótese pode ser usada para explicar a razão de haver mais crianças da escola particular que afirmaram terem ficado machucadas, 61,5\%, contrastando com 38,5\% da escola de menor poder aquisitivo $\left(\chi^{2}=5,739 ; g l=1 ; p=0,017\right)$. Assim, é possível que as crianças com privilegiadas condições de vida tenham uma noção diferente do que seja um machucado, ou seja, podem considerar pequenas marcas como algo muito mais grave e, ao contrário, crianças mais habituadas com eventos aversivos podem considerar marcas e machucados como menos graves. Gunnoe e Mariner (1997) afirmam que os efeitos das palmadas dependem do seu significado para a criança, e Baumrind (2001) completa que este significado depende do padrão presente na comunidade da criança.

A maneira de disciplinar sempre provoca algum tipo de reação na criança, boa ou ruim. Skinner (1953/1976) afirma que os comportamentos emocionais eliciados pela punição corporal são incompatíveis com o comportamento errado, por isso o comportamento cessa de imediato. No entanto, na maioria das vezes, eles também são incompatíveis com qualquer outro tipo de comportamento. Alguns destes comportamentos incompatíveis foram analisados a seguir.

Foi encontrada uma relação significativa entre os relatos sobre a intensidade da punição corporal e os seguintes comportamentos da criança: a tristeza $\left(\chi^{2}=4,907 ; g l=1 ; p=0,027\right)$, a raiva $\left(\chi^{2}=21,138 ; g l=1 ; p<0,001\right)$, o choro $\left(\chi^{2}=22,006 ; g l=\right.$ $1 ; p<0,001)$, e comportamento de desafio $\left(\chi^{2}=14,270 ; g l=1\right.$; $p<0,001)$. De todas as crianças que relataram ter ficado machucadas $(36,9 \%), 55,9 \%$ ficaram tristes e $49,3 \%$ sentiram raiva ao apanhar. Portanto, quanto mais forte os pais batem na criança, podendo até machucá-la, mais triste e com mais raiva ela fica. A tristeza e a raiva estão relacionadas com o choro, o qual também está intimamente relacionado com a intensidade da punição corporal. Dentre as crianças que já ficaram machucadas, a maior parte delas $(61,2 \%)$ chorou.

Outras reações são possíveis diante do recebimento de punições, tais como os comportamentos alternativos (Matos, 1982; Sidman, 1995; Skinner, 1953/1976). Um tipo de comportamento alternativo é a contra-agressão, o que nesta pesquisa foi investigado como comportamento de desafio.

O comportamento de desafio consiste em uma atitude de enfrentamento da criança em relação ao agente punidor. A criança pode enfrentar verbalmente, dizendo, por exemplo, que o tapa não doeu, ou pode fazê-lo por meio de atitudes agressivas em direção à pessoa que a puniu (ou até mesmo em outras pessoas), ou ainda repetir o mesmo comportamento punido na frente do agente punidor. O comportamento de desafio é explicado pela Análise do Comportamento, que indica que os eventos aversivos ou desagradáveis podem aumentar a variabilidade e a força dos comportamentos atingidos, bem como podem desinibir de maneira súbita e violenta, comportamentos anteriormente suprimidos ou reprimidos, ou seja, o comportamento punido ou outros reprimidos anteriormente podem aparecer com força e magnitude aumentadas (Matos, 1982).

O cruzamento dos dados entre comportamento de enfrentamento e relato de machucados revelou que a apresentação desse tipo de comportamento provocou punição com maior intensidade: de todas as crianças que enfrentaram a pessoa que as puniu, 60,8\% afirmaram já terem ficado machucadas. Porém as crianças que enfrentaram foram minoria $(12,4 \%)$.

A intensidade da punição corporal também se mostrou relacionada significativamente com sua freqüência $\left(\chi^{2}=30,452\right.$; $g l=2 ; p<0,001)$. Dentre as crianças que apanharam uma ou mais vezes por semana, a maior parte $(62,8 \%)$ já ficou machucada, enquanto a maioria daquelas que apanharam poucas vezes no ano nunca ficou machucada (70,3\%). Este dado está em desacordo com a posição de Baumrind (2001), que afirma que "não há evidência de que a punição corporal moderada aumente o risco de abuso". Essa relação pode ocorrer justamente pelo fato de o agente punidor não perceber resultados duradouros na correção de comportamentos inadequados, o que acaba levando-o a punir com maior frequiência e intensidade para obter os resultados imediatos que a punição oferece. Esses dados, mais uma vez, apontam a ineficácia desta prática educativa, de acordo com os argumentos de Skinner (1953/1976) e Sidman (1995). Este resultado indica que se deve refletir sobre o fato de que usualmente costumase dividir pais que maltratam de pais que apenas utilizam tapas, como se fossem naturezas diferentes. A violência deve ser definida pela sua função (infligir dano a outro) e não pela sua intensidade. Desta forma, é possível definir maus-tratos como um continuum das práticas coercitivas corporais, sendo que a freqüência e a intensidade são indicadores comuns, ou seja, os maus-tratos iniciam-se no primeiro degrau da escala de práticas coercitivas (Simons, Whitbeck, Conger, \& Chyi-In, 1991).

Essa ineficácia leva os pais a colocarem a culpa da indisciplina na criança, sendo que o erro está no método utilizado para educar. Este saber científico está de alguma forma presente no pensamento das crianças, que afirmaram: "Uma criança nunca aprende as coisas quando os pais batem" (Maria, 11 anos); "Às vezes uma boa conversa vale mais do que uma boa surra" (Rodrigo, 11 anos); "Se você não explicar o que a criança deve fazer, ela continuará fazendo" (Sandra, 9 anos); "As crianças devem ser ensinadas com boas palavras de educação" (Cláudia, 13 anos).

Apesar de as crianças apresentarem reações negativas diante da punição corporal, há uma tendência de elas seguirem o modelo de educação oferecido por seus pais ou responsáveis, como pode ser observado na frase de Natália de 9 anos: "Se a criança apanhar, quando ela ficar adulta, vai bater em seus filhos". Os dados mostraram uma clara relação entre o modelo dos pais e a expectativa de agir no futuro: das crianças que já apanharam, 63,4\% consideraram a palmada importante para um melhor comportamento $\left(\chi^{2}=29,123 ; g l=1 ; p<\right.$ $0,001)$ e $51,2 \%$ pretendem bater em seus filhos futuramente 
$\left(\chi^{2}=29,123 ; g l=1 ; p<0,001\right)$; e das que nunca apanharam, $78,3 \%$ não consideraram a palmada importante e $77,8 \%$ não pretendem bater em seus filhos.

Esses dados confirmam os resultados encontrados nas pesquisas de Murphy-Cowan e Stringer (1999) - que evidenciam que os pais punem fisicamente seus filhos na mesma medida em que foram punidos na infância - e de Graziano e Namaste (1990) - 93,2\% dos sujeitos apanharam na infância e pretendiam bater em seus futuros filhos. Esta passagem do modelo de uma geração para outra é uma das razões para que a punição corporal fosse mantida ao longo de tantos séculos como prática educativa, e forma um círculo vicioso muito difícil de ser questionado e quebrado. A perpetuação do modelo de educação que faz uso da punição corporal ocorre facilmente porque a punição corporal normalmente é acompanhada do discurso dos pais de que a criança merece a palmada e que isso é importante para ela. Como a punição corporal pressupõe uma relação hierárquica entre pais e filhos, na qual há um dominante (os pais) e um dominado (os filhos), a criança é facilmente persuadida por aquele que a domina de que o tapa vai transformá-la numa pessoa melhor (Cornet, 1997).

A associação entre "amor e dor" faz parecer para as crianças que as pessoas que mais a amam também têm o direito de lhe infligir dor. Igualmente nocivo é quando essa associação traz o componente de fazer da punição um estímulo discriminativo. Se a criança recebe pouca atenção dos pais em situações adequadas e passa a recebê-la somente quando se comporta inadequadamente, estes comportamentos passam a ser selecionados e aumentam de freqüência. Catania (1999) apresenta o exemplo de uma criança que foi surrada com muita intensidade, sendo que, em geral, tal comportamento paterno pode ser seguido por uma quantidade de atenção do pai arrependido que é maior do que a atenção nas interações cotidianas entre pai e filho. Se essa atenção do pai for reforçadora a ponto de suplantar os efeitos dos estímulos aversivos, estabelece-se um efeito discriminativo da punição, e a criança pode emitir comportamentos inadequados para, com isso, receber algum estímulo aversivo e depois a atenção do pai, ou seja, antes isso do que não receber qualquer tipo de atenção.

Por um lado, as crianças são persuadidas por seus pais a acreditarem que tapa é uma boa punição e tendem a repetir o modelo da palmada; por outro, elas recebem os tapas e as surras como algo desagradável ("a gente sente dor e quem é que gosta de apanhar?" Olívia, 10 anos), e assim manifestam reações negativas como a tristeza, a raiva, o medo e a ansiedade. Estes pontos contraditórios colocam a criança em uma situação de conflito em relação ao código moral sobre o que é certo e errado. Os próprios pais podem contribuir para a ambivalência dos filhos quando dizem que a criança precisa apanhar para ser corrigida, porém ela não pode bater no seu irmão ou no seu amiguinho, por exemplo. O conflito pode ser identificado nas respostas de uma parte das crianças em relação ao uso da punição corporal: $33,3 \%$ deles não concordaram com o fato de que tapa ensina, mas, contraditoriamente, concordaram que a criança deve ser punida ao comportar-se de forma inadequada $\left(\chi^{2}=72,466 ; g l=1 ; p<0,001\right)$. Muitas crianças $(33,3 \%)$ acharam que tapa não ensina, mas justificaram o seu uso em algumas situações, como "quando a criança faz uma coisa muito maldosa" (Lucas, 10 anos).

Além dos dados quantitativos desta pesquisa, pode-se fazer uma breve análise qualitativa de algumas frases escritas pelos participantes. Quando Pedro, 11 anos, afirma que "a criança que apanha vai querer bater em todo mundo", e Mariana, 9 anos, escreve: "bater é um jeito de ensinar que vai provocar violência no futuro, e as crianças que levam tapas sempre terão mais possibilidades de ter violência na vida", está presente a idéia de que a violência dentro de uma esfera da vida da criança gera violência em outras esferas (Straus \& McCord, 1998).

Isto significa que uma criança que apanha em casa pode utilizar o mesmo modelo para o seu ambiente escolar e/ou com seus colegas, como foi mostrado pela pesquisa realizada por Strassberg e colaboradores (1994). Assim como a relação coercitiva pode ser reproduzida pelas crianças em outros relacionamentos sociais, o sentido inverso também é provável. Muitos pais descontam em seus filhos uma agressividade vivida em outras relações sociais (Cornet, 1997). Isto fica claro na declaração de Júlia, 10 anos: "Minha avó desconta em nós as coisas que lhe acontecem".

\section{Conclusões}

Talvez os sentimentos contidos nas próximas páginas não sejam suficientemente modernos para despertar uma concordância geral; um hábito duradouro de não achar uma coisa como errada, dá a ela uma aparência superficial de estar certa, e levanta de pronto um formidável clamor em defesa do costume. Mas o tumulto logo se acalma. O tempo promove mais conversões do que raciocínio. (Thomas Paine, Introduction to Common Sense, 1776).

O objetivo da presente pesquisa foi descrever o uso de punição corporal em práticas educativas parentais, e os dados revelaram que, de fato, ela é utilizada com muita freqüência em crianças e em adolescentes, mesmo fora da faixa etária "recomendada" por autores (Baumrind, 2001; Larzerele et al., 1990, 1996) que admitem o seu uso (dois a seis anos). Apesar de entender que as metodologias das pesquisas realizadas para determinar relações causais entre a palmada e prejuízos ao desenvolvimento são muito diversificadas, dependendo de como a revisão da literatura é realizada, é possível encontrar argumentos pró ou contra o seu uso. Não é possível tratar deste tema sem levar em conta os argumentos da Análise do Comportamento que explicita as relações funcionais presentes nas relações coercitivas e tampouco sem pensar nos direitos humanos, e mais especificamente nos direitos da criança e do adolescente. Sem dúvida, este tema sempre vai perpassar o científico e alcançar os aspectos morais e éticos e até jurídicos, no caso de outros países, como a Suécia (e outros nove países) que promulgaram leis proibindo o uso de punições corporais contra os filhos.

Os resultados deste trabalho revelaram que a maioria absoluta das famílias das crianças e dos adolescentes 
pesquisados já utilizou ou ainda utiliza punições corporais, especialmente tapas e palmadas, como uma prática educativa, segundo o relato dos participantes. É importante ressaltar que tal prática foi empregada mais freqüentemente do que os castigos não-corporais, e uma hipótese levantada com base nos princípios estudados pela Análise do Comportamento é que o efeito imediato da palmada reforça o comportamento do agente punidor e, conseqüentemente, aumenta a probabilidade de ele usá-la em situações semelhantes, deixando de investir em outros métodos disciplinares que requerem um prazo maior para criação e manutenção de comportamentos adequados (reforçamento positivo) ou mesmo métodos que também têm elementos coercitivos, mas que necessitam da supervisão dos pais, como os castigos.

Um resultado que merece atenção é a relação entre punição corporal e freqüência: quanto mais freqüente foram as palmadas, mais os participantes afirmaram que ficaram machucados. Esta relação foge da "simples" palmada; pode ser incluída na categoria de abuso e indica uma relação de continuidade entre o "simples" tapa e a agressão, ou seja, eles não são de naturezas diferentes, mas pertencem a uma mesma categoria que varia em intensidade. A justificativa mais freqüente dos que são favoráveis à punição é que uma palmada é muito diferente de um espancamento. No entanto, a palmada é a parte inicial de uma escala cuja natureza e princípios são os mesmos de um espancamento. Bater de leve ou dar uma surra são atitudes que seguem um mesmo princípio e não é possível delimitar onde termina um e começa o outro. Quem dá um tapa, será capaz de dar um tapa um pouco mais forte se o primeiro não resolver, pois são tapas da mesma forma. Então, qual o limite entre palmada e espancamento? Quando é possível dizer que uma palmada foi muito forte? O limite está em quem bate ou em quem apanha?

A famosa regra de ouro anda esquecida nas questões de disciplina dos filhos: não faça aos outros o que você não quer que façam com você. Não parece simples? A criança tem o direito de ser respeitada em sua dignidade, e o uso da punição corporal contraria os direitos humanos, como afirmou Lansdown (2001). Da mesma forma que os pais normalmente exigem respeito por parte dos filhos, também os filhos merecem respeito dos pais. Dentro deste respeito encontra-se a questão de aceitar o filho com suas limitações, não exigindo perfeição e infalibilidade. A tolerância faz bem em todas as esferas dos relacionamentos humanos, como mostra Débora de 12 anos: "todo mundo erra e faz coisas erradas". Além disso, a punição acaba por tratar a criança como um objeto, e é assim que elas podem se sentir, porém "a criança não é objeto para bater" (Cyntia, 10 anos).

A punição corporal tem um efeito imediato - a supressão imediata do comportamento - e eficaz para o agressor, o que reforça o seu comportamento de bater. Quem recebe a punição corporal geralmente sente dor física e também seus subprodutos emocionais, tais como raiva, culpa, vergonha, medo e ansiedade, que podem demorar a cicatrizar. Além disso, podem ocorrer comportamentos de contra-ataque, a apatia ou ainda comportamentos de fuga e esquiva para livrar-se da punição corporal e, neste caso, as crianças deixam de emi- tir o comportamento punido - pelo menos quando os agentes punidores estão por perto - não por terem aprendido o correto, mas para escaparem dos tapas e surras, como mostra Rodrigo, 11 anos: "as crianças ficam com medo e não fazem mais aquilo que fizeram quando os pais estão por perto" (Rodrigo, 11 anos). Outro fator importante é que ambientes em que há predominância de punições tornam-se eles mesmos punitivos e reage-se a eles como a punidores naturais. De acordo com Sidman (1995, p. 103), "as pessoas que usam punição tornam-se elas mesmas punidores condicionados. (...) Qualquer um que use choque torna-se um choque". A frase de Camila, 10 anos, confirma: "O filho vai se afastando cada vez mais dos pais quando apanha".

A punição corporal é uma forma de opressão e de coerção, e ela, infelizmente, encontra eco favorável na própria estrutura familiar. Todo tipo de agressão é injustificável, tanto do ponto de vista ético, moral, social, humano, quanto psicológico e científico. Ela simplesmente perpetua um círculo vicioso no qual o agredido pode passar a tornar-se agressor. "Violência só leva à violência" (Helder, 9 anos), afirma sabiamente um participante dessa pesquisa, concordando com o modelo de coerção proposto por Patterson e colaboradores (1992), no qual o comportamento anti-social é aprendido em primeiro lugar no ambiente familiar. Em uma recente metaanálise que examinou 88 estudos, Gershoff (2002) estudou comportamentos positivos e negativos associados à punição corporal na infância e encontrou forte associação entre punição corporal e agressão infantil e comportamento antisocial. Gershoff reporta que o único efeito positivo encontrado para a punição corporal foi a imediata obediência da criança e argumenta que, enquanto não forem encontrados efeitos benéficos para as palmadas, e não apenas ausência de efeitos negativos, os psicólogos não podem ter a responsabilidade de recomendar o seu uso.

É claro que a punição corporal como prática educativa não é uma variável isolada, pois ela ocorre em um contexto que inclui outras práticas e diferentes estilos parentais. Se os pais forem muito competentes e equilibrados em níveis de exigência e responsividade, uma palmada ocasional não causa um dano terrível, de acordo com Baumrind (2001). Então, se os pais são muito competentes, é preciso fazer uma pergunta retórica: por que usar as palmadas? Disciplina não é um sinônimo para punição e muito menos para punição corporal. Disciplinar é ajudar uma criança a desenvolver seu autocontrole, estabelecer limites, ensinar comportamentos adequados e corrigir os inadequados. Disciplinar também envolve encorajar a criança, ajudá-la a desenvolver a sua auto-estima e sua autonomia, ou seja, prepará-la para enfrentar o mundo sem que precise emitir comportamentos simplesmente para evitar as punições e aprender que a coerção é uma solução inaceitável para a resolução de problemas. A questão da punição, como estratégia disciplinar, ultrapassa o conhecimento da ciência e chega à ética; é preciso entender "quando e por que os pais escolhem a punição como uma tática de socialização" (Parke, 2002, p. 600) e que direito temos para infringir dor a uma criança se há tantas outras possibilidades e outros métodos. 
E para finalizar, nada melhor do que os conselhos de três crianças que participaram desta pesquisa, as quais enfatizaram o diálogo como o grande método a ser utilizado, pois pressupõe participação ativa no processo de educar e preparar uma criança para o mundo: "É preciso fazer campanha para acabar com as surras; uma outra coisa que os pais podem fazer é, todo mês, dar uma folha para a criança escrever o que sente e depois conversar com os pais" (Pedro, 10 anos); "Eu quero dizer que é para os pais não baterem muito forte e para conversarem duas vezes antes de bater" (Regina, 11 anos); "Educação é tudo! Eduque seu filho na maneira adequada. Com limites, mas sem violência" (Tatiana, 14 anos).

\section{Agradecimentos}

Agradecemos os comentários e as sugestões do Prof. Dr. Marcus Bentes de Carvalho Neto (UFPA).

\section{Referências}

Ariès, P. (1978). História social da criança e da família. Rio de Janeiro: Zahar. Azevedo, M. A., \& Guerra, V. N. (1997). Infância e violência doméstica: fronteiras do conhecimento. São Paulo: Cortez.

Azevedo, M. A., \& Guerra, V. N. (2001). Mania de bater. São Paulo: Iglu.

Azevedo, M. A., \& Guerra, V. N. (2002). Palmada já era. São Paulo: Autores.

Bachar, E., Canetti, L., Bonne, O., DeNour, A. K., \& Shaley, A. Y. (1997). Physical punishment and signs of mental distress in normal adolescents. Adolescence, 32, 945-958.

Badinter, E. (1985). Um amor conquistado: o mito do amor materno. Rio de Janeiro: Nova Fronteira.

Baumrind, D. (2001). Does relevant research support a blanket injunction against disciplinary spanking by parents? Comunicação apresentada na $109^{\mathrm{a}}$ Convenção Anual da American Psychological Association. Obtido em 29 de abril de 2002, de http://ihd.berkeley.edu/baumrindpaper.pdf.

Bettner, B. L., \& Lew, A. (2000). Talking to parents about hitting. Journal of Individual Psychology, 56, 110-114.

Bodenhamer, G. (1995). Parent in control. Nova York: Fireside.

Bryant, S. L., \& Range, L. M. (1995). Suicidability in college women who were sexually and physically abused and physically punished by parents. Violence and Victims, 10(3), 195-201.

Catania, A. C. (1999). Aprendizagem: comportamento, linguagem e cognição. Porto Alegre: Artes Médicas.

Cornet, J. (1997). Faut-il battre les enfants? Paris: Hommes et Perspectives.

Day, D. E., \& Roberts, M. W. (1983). An analysis of the physical punishment component of a parent training program. Journal of Abnormal Child Psychology, 11, 141-152.

Frias-Armenta, M. (1999). Law, psychology, family relations and child abuse in Mexico. Dissertation Abstracts International: Section B: The Sciences and Engineering, 60 (4-B), 1913.

Gallardo, J. A. (1988). Malos tratos a los niños. Madri: Narcea.

Garbarino, J. (1999). Lost boys. Nova York: Free Press.

Gershoff, E. T. (2002). Corporal punishment by parent and associated child behaviors and experiences: a meta-analytic and theoretical review. Psychological Bulletin, 128(4), 539-579.

Glueck, S., \& Glueck, E. (1968). Delinquents and nondelinquents in perspective. Cambridge, Massachusetts: Harvard University Press.

Gomide, P. I. C. (2001). Efeito das práticas educativas no desenvolvimento do comportamento anti-social. In M. L. Marinho \& V. E. Caballo (Orgs.), Psicologia Clínica e da Saúde (pp. 33-54). Londrina: Editora da UEL/Granda: APICSA.

Graziano, A. M., \& Namaste, K. A. (1990). Parental use of physical force in child discipline: a survey of 679 college students. Journal of Interpersonal Violence, $5,449-463$
Guerra, V. N. A. (1998). Violência de pais contra filhos: a tragédia revisitada. São Paulo: Cortez.

Gunnoe, M. L., \& Mariner, C. L. (1997). Toward a developmental-contextual model of the effects of parental spanking on children's aggression. Archives of Pediatrics Adolescent Medicine, 151, 768-775.

Hyman, I. A. (1997). The case against spanking. São Francisco: Jossey-Bass.

Lansdown, G. (2001). Children's rights and domestic violence. Child-Abuse Review, 9(6), 416-426.

Larzelere, R. E. A. (2000). Child outcomes of nonabusive and customary physical punishment by parents: an updated literature review. Clinical Child and Family Review, 3(4), 199-221.

Larzelere, R. E., Klein, M., Schumm, W. R., \& Alibrando, S. A. (1990). Relations of spanking and other parenting characteristics to self-esteem and perceived fairness of parental discipline. Psychological Reports, 64, 1140-1142.

Larzelere, R. E., Schneider, W. N., Larson, D. B., \& Pike, P. L. (1996). The effects of discipline responses in delaying toddler misbehavior recurrences. Child and Family Behavior Therapy, 18, 35-57.

Marinopoulos, S. (1998). Avant l'adoption: 1'abandon. Journal des Psychologues, 153, 23-26.

Matos, M. A. (1982). A ética no exercício de controles aversivos. Boletim de Psicologia, 33(61), 128-133.

Mello Neto, G. A. R. (1998). Criança como erro, pecado e máquina. Psicologia em Estudo, 3(1), 69-103.

Morris, J. D. (1996). The normative influence of social network members on mothers' attitudes toward corporal punishment. Dissertation Abstracts International: Section B: The Sciences and Engineering, 57(1-B), 0765.

Murphy-Cowan, T., \& Stringer, M. (1999). Physical punishment and the parenting cycle: a survey of Northern Irish parents. Journal of Community and Applied Social Psychology, 9, 61-71.

Parke, D. R. (2002). Punishment revisited - science, values, and the right question: comment on Gershoff (2002). Psychological Bulletin, 128(4), 596-601.

Patterson, G., Reid, J., \& Dishion, T. (1992). Antisocial boys. Eugene, Oregon: Castalia.

Postman, N. (1999). O desaparecimento da infância. Rio de Janeiro: Graphia.

Reid, J. B., Taplin, P. S., \& Lorber, R. A. (1981). A social interactional approach to the treatment of abusive families. In R. B. Stuart (Org.), Violent behavior: social learning approaches to prediction, management, and treatment ( $\mathrm{pp}$. 83-101). Nova York: Brunner/Mazel.

Roberts, M. W., \& Powers, S. W. (1990). Adjusting chair timeout enforcement procedures for oppositional children. Behavior Therapy, 21, 257-271.

Roig, A. M., \& Ochotorena, J. P. (1993). Maltrato y abandono en la infancia. Barcelona: Martínez Roca.

Seligman, M. E .P. (1975/1977). Desamparo: sobre depressão, desenvolvimento e morte. São Paulo: Hucitec/EDUSP.

Sidman, M. (1995). Coerção e suas implicações. Campinas: Psy.

Simons, R. L., Whitbeck, L. B., Conger, R. D., \& Chyi-In, W. (1991). Intergenerational transmition of harsh parenting. Developmental Psychology, 27, 159-171.

Skinner, B. F. (1976). Ciência e comportamento humano. São Paulo: EDART. (Texto original publicado em 1953).

Stormshak, E. A., Bierman, K. L., McMahon, R. J., \& Lengua, L. J. (2000). Parenting practices and child disruptive behavior problems in early elementary school. Journal of Clinical Child Psychology, 29, 17-29.

Strassberg, Z., Dodge, K. A., Pettit, G. S., \& Bates, J. E. (1994). Spanking in the home and children's subsequent aggression toward kindergarten peers. Development and Psychopathology, 6, 445-461.

Straus, M. A. (1991). Discipline and deviance: Physical punishment of children and violence and other crimes in adulthood. Social Problems, 38, 133-154.

Straus, M. A. (2000). Corporal punishment and primary prevention of physical abuse. Child Abuse and Neglect, 24(9), 1109-1114. 
Straus, M. A. (2001). Murray Straus' comments on Baumrind's data. Obtido em 17 de maio de 2002 de http://www.nospank.net/straus10.htm.

Straus, M. A., \& McCord, J. (1998). Do physically punished children become violent adults? In S. Nolen-Hoeksema (Org.), Clashing views on abnormal psychology: a taking sides custom reader (pp. 130-155). Guilford, Connecticut: Dushkin/Mcgraw-Hill.

Straus, M., \& Stewart, J. H. (1999). Corporal punishment by American parents: national data on prevalence, chronicity, severity, and duration, in relation to child and family characteristics. Clinical Child and Family Psychology Review, 2, 55-70.

Weber, L. N. D. (2001). Quem ensina a violência? Conjuntura Social, 6, 38-43. Weber, L. N. D., Viezzer, A. P., Brandenburg, O. J., \& Zocche, C. R. E. (2002). Famílias que maltratam: uma tentativa de socialização pela violência. PsicoUSF, 7(1), 157-167.
Weber, L. N. D., Viezzer, A. P., \& Brandenburg, O. J. (2003). Estilos parentais e o desenvolvimento da criança e do adolescente e palmadas e surras: ontem, hoje e amanhã. In M. Z. Brandão, F. C. Contem, F. S. Brandão, Y. K. Ingberman, C. B. Moura, V. M. Silva, \& S. M. Oliane (Orgs.), Sobre comportamento e cognição: a história e os avanços, a seleção por conseqüências em ação. Santo André, SP: ESETec Editores Associados.

Welsh, R. S. (1976). Severe parental punishment and delinquency: a developmental theory. Journal of Clinical Child Psychology, 5, 17-21.

Whipple, E. E., \& Richey, C. A. (1997). Crossing the line from physical discipline to child abuse: how much is too much? Child Abuse and Neglect, $21,431-444$.

Wilson, J. Q., \& Hernstein, R. J. (1985). Crime and human nature. Nova York: Simon \& Schuster.

1 Todos os nomes citados nos depoimentos das crianças são fictícios.

Lidia Natalia Dobrianskyj Weber, doutora em Psicologia Experimental pela Universidade de São Paulo, é psicóloga e professora no departamento de Psicologia e no mestrado em Psicologia da Infância e da Adolescência da Universidade Federal do Paraná. Endereço para correspondência: Universidade Federal do Paraná; Praça Santos Andrade, 50/1; CEP 80060-000; Curitiba, PR. Fone/fax: (41) 310-2644. E-mail: lidia@ ufpr.br Ana Paula Viezzer é bolsista de iniciação científica na Universidade Federal do Paraná. Olivia Justen Brandenburg é bolsista de iniciação científica na Universidade Federal do Paraná. 